DOI: 10.4274/tpa.1170

\title{
Ada çayı yağının ağızdan kullanımına bağılı süt çocuğunda konvülziyon
}

\section{Convulsion in infants as a result of oral use of garden sage}

\author{
Vefik Arıca, Seçil Arıca*, Murat Tutanç, Sedat Motor ${ }^{\star \star}$, Vicdan Köksaldı Motor ${ }^{\star \star \star}$, Murat Doğan ${ }^{\star \star \star \star}$ \\ Mustafa Kemal Üniversitesi Tip Fakültesi, Çocuk Sağığı ve Hastallkları Anabilim Dall, Hatay, Türkiye \\ *Mustafa Kemal Üniversitesi Tıp Fakültesi, Aile Hekimliği Anabilim Dalı, Hatay, Türkiye \\ **Mustafa Kemal Üniversitesi Tip Fakültesi, Tibbi Biyokimya Anabilim Dall, Hatay, Türkiye \\ ${ }^{* * \star M u s t a f a}$ Kemal Üniversitesi Tip Fakültesi, Enfeksiyon Hastallkları Anabilim Dall, Hatay, Türkiye \\ ****istanbul Özel Erdem Hastanesi, Çocuk Sağı̆̆ı̆ ve Hastalıkları Kliniği, Istanbul, Türkiye
}

\section{Özet}

Ada çayı olarak bilinen salvia officinalis bitkisi çeşitli klinik durumlarda halk tarafından kullanılmakta olup özellikle aktarlar tarafından temin edilmektedir. Salvia officinalis adlı ada çayının diüretik, antienflamatuar, antimikrobiyal, antiseptik, ekspektoran, spazmolitik ve terlemeyi arttırıcı olarak kullanımı bilinmektedir. Bu olgumuzda, iki aylık bir bebekte aktar tarafından deriye sürülerek kullanılması için hazırlanan, ancak yanlışlıkla ağızdan kullanılan ada çayı yağına bağlı konvülziyonla gelen bir zehirlenme olgusu sunuldu. (Türk Ped Arş 2012; 47: 67-8)

Anahtar sözcükler: Ada çayı yağı, konvülziyon, zehirlenme

\section{Summary}

Salvia officinalis is a plant known as Garden Sage and it is used by the community in case of various clinical conditions. Herbalists are the right destinations to provide this special plant. Salvia officinalis is known to be used for its diuretic, anti-inflammatory, antimicrobial, antiseptic, expectorant, spasmolytic and diaphoretic effects. In this case study, a case of intoxication in which a 2-month old infant who presented with convulsion due to accidental oral use of garden sage oil which was actually prepared for topical use by a herbalist is reported. (Turk Arch Ped 2012; 47: 67-8)

Key words: Convulsion, garden sage oil, intoxication

\section{Giriș}

Gelişmekte olan ülkelerde son 20-25 yılda, bitkisel ilaçlar ve "alternatif" tıp tekniklerinin kullanımı yaygınlaştığı, hatta bazı üniversitelerde bilim kurulmakta olup, bu yöntemlerle ilişkili yan etki ve komplikasyonlarda artış olduğu bildirilmiştir. Yenidoğan ve süt çocuklarında genelde en sık, rezene, papatya ve anason çayları gaz giderici olarak kullanılmakta birlikte kabızlıkta, anne sütü arttırıması ve enfeksiyonlara karşı da kullanılabilmektedir (1). Bu bitkiler genelde ağızdan kullanııı; fakat vücuda sürülen kullanımları da mevcuttur. Normal dozlarda genelde yan etki görülmez. Ancak yüksek dozda veya yerel sürülme için hazırlanmış özel şekillerin ağızdan kullanılması sonucu zehirlenme olguları bildirilmiştir (1).

Bu olgumuzda, bebekte karındaki şişliği, gazı ve ağlama krizlerini giderme sağlama amacıyla belirli bir süre damla formları uygulanmış ancak bebeğin rahatlamaması üzerine aktardan hazırlatılan ada çayı yağının (salvia officinalis) yanlışlıkla yerel kullanımı yerine ağızdan yüksek dozda uygulanımı sonucu gelişen konvülziyon olgusu sunulmuştur.

\section{Olgu}

İki aylık kız bebek, acil polikliniğe sürekli ağlama, aniden başlayan huzursuzluk, ellerde kollarda kasılma, gözlerde

Yazışma Adresi/Address for Correspondence: Dr. Vefik Arıca, Mustafa Kemal Üniversitesi Tıp Fakültesi, Çocuk Sağlı̆ı ve Hastalıkları Anabilim Dalı, Hatay, Türkiye Tel: +90 3262196 00/2925 Faks: +90 3262148214 E-posta: vefikarica@hotmail.com Geliş Tarihi/Received: 01.02.2010 Kabul Tarihi/Accepted: 28.06.2010 Türk Pediatri Arşivi Dergisi, Galenos Yayınevi tarafından basılmıştır. / Turkish Archives of Pediatrics, published by Galenos Publishing 
titreme, kusma ve morarma şikayetleriyle getirildi. Öyküde 22 yaşındaki annenin, 24 yaşındaki babanın zamanında ilk gebelikten doğmuş bebeğin, sezaryen ile 3240 gram ağırlığında, $49 \mathrm{~cm}$ boyunda, $34 \mathrm{~cm}$ baş çevresiyle doğduğu, doğum öncesi ve sonrasına ait geçmişinde bir özellik olmadığı ve bize başvurmadan yaklaşık iki saat önce karın bölgesine masaj uygulamayla gaz giderme ve sancı giderme amacıyla aktarda özel hazırlatılan ada çayı yağının bir inmal sonucu yanlışlıkla bir tatlı kaşığı kadar bebeğe içirildiği ifade ediliyor.

Fizik muayene bulgusu olarak, rektal Isı 37,0 derece, kalp atım hızı 136 vuru/dak ritmik, solunum sayısı 55 /dak, ağılık 4300 gram (\%25-50), boy $53 \mathrm{~cm}(\% 25-50)$, baş çevresi $38 \mathrm{~cm}$ (\%25-50) idi. Hastada çok az solunum sıkıntısı vardı, derin tendon reflekslerinde artma, aşil ve çenede klonus, opistotonus ve gözlerde nistagmus mevcuttu, acile gelişinde ellerde ve kollarda tonik-klonik tarzda konvülziyon geçiriyordu.

Laboratuvarda, lökosit sayısı $12500 / \mathrm{mm}^{3}$, hemoglobin 14 $\mathrm{gr} / \mathrm{dL}$, hematokrit \%42, trombosit sayısı $420000 / \mathrm{mm}^{3}$ idi. Kan şekeri $112 \mathrm{mg} / \mathrm{dL}$, sodyum $136 \mathrm{mEq} / \mathrm{L}$, potasyum 3,7 mEq/L ve iyonize kalsiyum 4,65 mmol/L, AST: $47 \mathrm{IU} / \mathrm{L}$, ALT: $25 \mathrm{IU} / \mathrm{L}$, CRP: 0,6 mg/dL kan gazı değerleri normal olarak saptandı.

Bebeğin hemen ağız yolu açık tutuldu, uygun pozisyon verildi ağız içi aspire edildi, 4 It/dak'dan oksijen verildi ve hemen damar yolu açılarak sıvı takıldı ve $10 \mathrm{mg} / \mathrm{kg}$ 'dan yükleme fenobarbital uygulandı ve bebeğin konvülziyonu durduruldu. Öykü alındıktan sonra zehir danışma aranılarak adli rapor tutuldu, hastanın midesi yıkanarak aktif kömür uygulandı ve yatış yapılarak gözleme alındı. Yatışından 12 saat sonra derin tendon refleksleri normale döndü ve klonus kayboldu, opistotonus ve hipertonisite iyice azaldı. Yirmi dört saat sonra hasta tamamen düzeldi, ağızdan alım arttı, konvülziyon tekrarlamadı ve fenobarbital devam dozuna intiyaç kalmadı. Zehir danışma bilgisiyle 48 saat sonra kontrollere gelmek üzere taburcu edildi. Yapılan kontrollerde çekilen uyku elektroansefalografisinde herhangi bir sorun ve konvülziyon ifade edilmedi.

\section{Tartışma}

Ada çayı yapraklarının damıtıması ile elde edilen ada çayı yağı; salvene, pinene, camphor, cineole, borneol, thujone, sponin, diterpene, phenolic asit, salviatanin, ürsokolik asit, kafeik asit ve flavonoidleri içerir (1-3).
Ada çayı (salvia officinalis) değişik şekillerde sedatif, antienflamatuar, antimikrobiyal, spazmolitik, antioksidan, antitümör, tansiyon düşürücü, diüretik, terlemeyi arttırıcı, antiseptik özellikleri ile koroner kalp hastalıkları, kronik bronșit, astım, kronik böbrek yetersizliği, siroz, dismenore, uyuyamama, infantil kolik, dispepsi, Alzheimer hastalığı gibi çeşitli klinik durumlarda bitkisel ilaç olarak kullanılmaktadır $(1,2,4)$.

Süt çocukluğu döneminde ülkemizde, en sık kullanılan bitkisel ilaçlar kabızık ve infantil kolik durumlarında kullanılan rezene, papatya, anason çayları ve badem yağıdır. Sık kullanılan bu bitkisel ilaçların zehirlenme tablolarında, apne, merkezi sinir sitem depresyonu, kusma ve ishal saptanırken $(1,5,6)$, bu olgumuzda opistotonus, derin tendon reflekslerinde artma, konvülziyon gibi merkezi sinir sistemi uyarımına bağlı belirtiler ortaya çıkmışır.

Ada çayının damıtıımasıyla elde edilen ada çayı yağının, thujone, camphor ve cineole içerdiği, bu maddelerin epileptojenik özellik taşıdığı ve deneysel bir çalışmada diğer bitkisel ilaçlarla karşılaşııııldığında çok daha düşük dozlarda konvülziyonla belirgin zehirlenme tablolarına neden olduğu bildirilmiştir (7). Olgumuzda, bir tatı kaşığı miktarında ada çayı yağının ağızdan yanlışlıkla alımının süt çocukluğu döneminde konvülziyonla giden zehirlenme oluşturmuş olması, belirtilen deneysel çalışma ile uyumlu gözükmektedir.

Sonuç olarak, nedeni saptanamayan erken süt çocukluğu dönemindeki konvülziyonlarında bitkisel ilaçlara bağlı akut zehirlenmenin etiolojiden sorumlu olabileceği sorgulanmalı ve ada çayı yağının yerel kullanımı yerine ağızdan yanlış kullanımına bağlı konvülziyon ve hipertonisite ile belirgin hipereksitasyon oluşabileceği unutulmamalıdır.

\section{Kaynaklar}

1. Baytop T. Türkiye'de bitkilerle tedavi. İstanbul: İstanbul Üniversitesi Eczacılık Fakültesi Yayınları, 1984; 284-6.

2. Baricevic D, Sosa S, Loggia RD, et al. Topical anti-anflammatory activity of Salvia officinalis L. Leaves: the relevance of ursolic asid. J Ethnopharmacol 2001; 75: 125-32.

3. Lu Y, Foo LY. Polyphenolics of Salvia-a review. Phytochemistry 2002; 59: $117-40$

4. Miura K, Kikuzaki H, Nakatani N. Apianane terpenoids from Salvia officinalis. Phytochemistry 2001; 58: 1171-5.

5. Niggeman B, Grüber C. Side-effects of complementary and alternative medicine. Allergy 2003; 58: 707-16.

6. Ko R. Adverse reactions to watch in patients using herbal remedies. WJM 1999; 171: 181-6.

7. Burkhard PR, Burkhardt K, Haenggeli CA, Landis T. Plant-induced seizures: reappear-ance of an old problem. J Neurol 1999; 246: 667-70. 